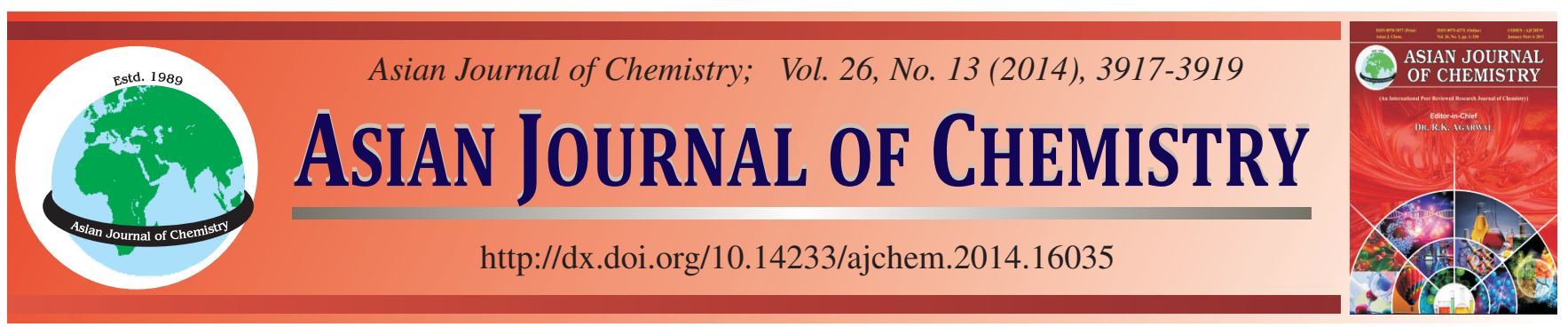

\title{
Indirect Determination of Thiocyanate Ions in Seawater by Methyl Isobutyl Ketone Extraction-Atomic Fluorescence Spectrometry
}

\author{
JiAnPING Lu*, Jinglong Bu, HuQuan Ni and YangJIE HuANG
}

College of Chemistry and Chemical Engineering, Guangxi University, Nanning 530004, P.R. China

*Corresponding author: E-mail: ljianpi@ hotmail.com

\begin{abstract}
The complex of thiocyanate ions and $\mathrm{Hg}^{2+}$ in aqueous phase was extracted into methyl isobutyl ketone, then the organic phase combined with reductant was introduced simultaneously into atomic fluorescence spectrometer, where $\mathrm{Hg}$ was determined in terms of thiocyanate ions. The vatiations of extractants, aqueous acidity, volume of extractnt, shaking and rest times were investigated. The experimental results indicated that the extraction efficiency of the complex decremented as the acidity of aqueous phase incremented. On the other hand, it increased as volume of methyl isobutyl ketone increased, then approached to be constant. In optimum condition, the extraction efficiency could reach more than $95 \%$. The method was linear in the range of $0.2-150 \mathrm{ng} / \mathrm{mL}$, and the minimum detectable limit of 1.33 $\mathrm{ng} / \mathrm{mL}$ was obtained. This method of high sensitivity and good accuracy was applied to determine thiocyanate ions in seawater.
\end{abstract}

Keywords: Methyl isobutyl ketone, Thiocyanate ions, Seawater, Extraction.

\section{INTRODUCTION}

Currently, the fast growth of global population and the rapid development of industries lead to the dramatical increase of clean water requirement and waste water discharge. Each year, around 420 billion tons of waste water in the whole world are discharged into rivers, lakes and seas, resulting in water pollution ${ }^{1}$. When thiocyanate ions in sewage, industrial effluents and pesticide residue solution is chlorinated during the waste water treatment, the more toxic product cyanuric chloride $^{2}$ is created to generate a significant impact on environment, human health and aquatic organisms. Thiocyanate ions could inhibit the transportation of iodine in human body, giving rise to endemic goiter ${ }^{3}$. Its toxicity is realized by converting it to cyanide through thiocyanate acid oxidase $\mathrm{s}^{4}$.

A number of methods of determining thiocyanate ions have been reported, such as chromatography ${ }^{5-8}$, spectrometry ${ }^{9-11}$, electrochemistry ${ }^{12,13}$, titration $^{14,15}$ if the amount is high enough and other methods ${ }^{16}$. However, the determination of thiocyanate ions by atomic fluorescence spectrometry has not been found in literature. The proposed method is based on the formation of the compound between thiocyanate ions and $\mathrm{Hg}^{2+}$ in an acidic medium. After the compound is extracted into an organic solvent and introduced into the instrument, the mercury is determined proportionally to thiocyanate ions, thus, the amount of thiocyanate ions is measured. Due to the direct introduction of organic solvent, it necessitates the carrier flow and reductant to be dissolved into an organic solvent to guarantee mercury in the sample extract to be reduced into its element. Hydrochloric acid diluted and potassium borohydride dissolved with ethanol, respectively, were prepared for both carrier flow and reductant solution. Excellent separation and enrichment of the analyte were obtained, making it possible to determine thiocyanate ions with merits of low interference and detection limit.

\section{EXPERIMENTAL}

AFS-2202E Atomic fluorescence spectrometer (Beijing Kechuang Haiguang Instrument Inc, China) equipped with mercury hollow cathode lamp (Beijing General Institute for Nonferrous Metals, China) was used to determine the target element.

Stock solution of thiocyanate ions: $\mathrm{KSCN}$ of $0.1672 \mathrm{~g}$, which was dried in an oven for $4 \mathrm{~h}$ at $100{ }^{\circ} \mathrm{C}$ and stored in a desiccator, was accurately weighed, completely dissolved with a small quantity of water, then transferred into a $100 \mathrm{~mL}$ volumetric flask and diluted to mark. The stock solution was $1 \mathrm{mg} / \mathrm{mL}$ thiocyanate ion. When needed, the stock solution was prepared to $1 \mu \mathrm{g} / \mathrm{mL}$.

Mercury work solution: The required solution was prepared using the mercury standard solution of $1 \mathrm{mg} / \mathrm{mL}$ (National Center of Standard Materials of China).

$\mathrm{NaOH}$ solution (2\%): $\mathrm{NaOH}$ of $2 \mathrm{~g}$ was weighed and made $100 \mathrm{~mL}$ using water. 
Potassium borohydride solution (10 g/L): Potassium borohydride $(1 \mathrm{~g})$ was weighed and dissolved in $200 \mathrm{~mL}$ of $2 \% \mathrm{NaOH}$, then anhydrous ethanol was added to $100 \mathrm{~mL}$. Freshly prepared when used.

Seawater samples: Samples were from offshores of municipal Xianmen in Fujian province and municipal Beihai in Guangxi province, China; hydrochloric acid, nitric acid, methyl isobutyl ketone, anhydrous ethnol, ethyl acetate, petroleum ether, isoamyl alcohol, sodium hydroxide, potassium thiocyanate and potassium borohydride were all of analytic grades. Water was double distilled water.

\section{Experimental processes}

Instrumental parameters: Negative voltage $270 \mathrm{~V}$, lamp current $20 \mathrm{~mA}$, the height of atomizer $10 \mathrm{~mm}$, carrier gas flow rate $400 \mathrm{~mL} / \mathrm{min}$, shield gas flow rate $900 \mathrm{~mL} / \mathrm{min}$, delay time $1 \mathrm{~s}$, read time $10 \mathrm{~s}$, read mode: peak; measurement mode: standard calibration curve.

Sample preparation: The seawater samples were settled for while to let the sediments precipitate, if some floating impurities exited, filtration had to be conducted. In a $50 \mathrm{~mL}$ volumetric flask, $20 \mathrm{~mL}$ of $1: 1 \mathrm{HNO}_{3}$ were added, then, the supernatant was poured the flask to mark, which made the acidity of solution $0.025-0.05 \mathrm{~mol} / \mathrm{L}$. The volume of seawater sample was taken as $30 \mathrm{~mL}$ when the calculation of result was conducted.

Experimental method: Mercury solution (1 mL) with concentration of $1 \mu \mathrm{g} / \mathrm{mL}$ was pipetted into a $60 \mathrm{~mL}$ separatory funnel, an appropriate amount of thiocyanate solution and $1 \mathrm{~mL}$ nitric acid of $1 \mathrm{~mol} / \mathrm{mL}$ were added and the final volume was made to $10 \mathrm{~mL}$ using water and was mixed throughly. After the reaction inside the flask took place for a while, $8 \mathrm{~mL}$ of methyl isobutyl ketone was added for extraction. The solution rested for $0.5 \mathrm{~h}$ after the extraction completed. The organic phase was transferred into a $10 \mathrm{~mL}$ colorimetric tube and the mercury was determined, a blank was prepared and determined in parallel to the samples.

\section{RESULTS AND DISCUSSION}

Selection of organic solvents and acidity: When $1.5 \mathrm{~mL}$ thiocyanate of $1 \mu \mathrm{g} / \mathrm{mL}$ and $1 \mathrm{~mL}$ mercury of $1 \mu \mathrm{g} / \mathrm{mL}$ were added into a separatory funnel according to experimental method, the routinely used organic solvents isopentanol, diethyl ether, petroleum ether, methyl isobutyl ketone and ethyl acetate were investigated in the range of $0-5 \mathrm{~mol} / \mathrm{mL}$ nitric acid. Result demonstrated that isopentanol and methyl isobutyl ketone produced almost the same extraction efficiency when the acidity was $0.1 \mathrm{~mol} / \mathrm{mL}$ (Fig. 1). However, the alcohol was more volatile than ketone and partially dissolved in water. In a result, nitric acid of $0.1 \mathrm{~mol} / \mathrm{mL}$ and methyl isobutyl ketone were used as extraction acidity and solvent, respectively.

Selection of solvent volume: In 11 separatory funnels of $60 \mathrm{~mL}$, according to the method, $1 \mathrm{~mL}$ of $1 \mu \mathrm{g} / \mathrm{mL}$ mercury ion, $1.5 \mathrm{~mL}$ of $1 \mu \mathrm{g} / \mathrm{mL}$ thiocyanate and $1 \mathrm{~mL}$ of $1 \mathrm{~mol} / \mathrm{mL}$ $\mathrm{HNO}_{3}$ were added and $6.5 \mathrm{~mL}$ water were joined to make final volume of $10 \mathrm{~mL}$ in each. Then, the extraction was conducted with variation of different volume of methyl isobutyl ketone. It was observed that the extraction efficiency was in agreement of

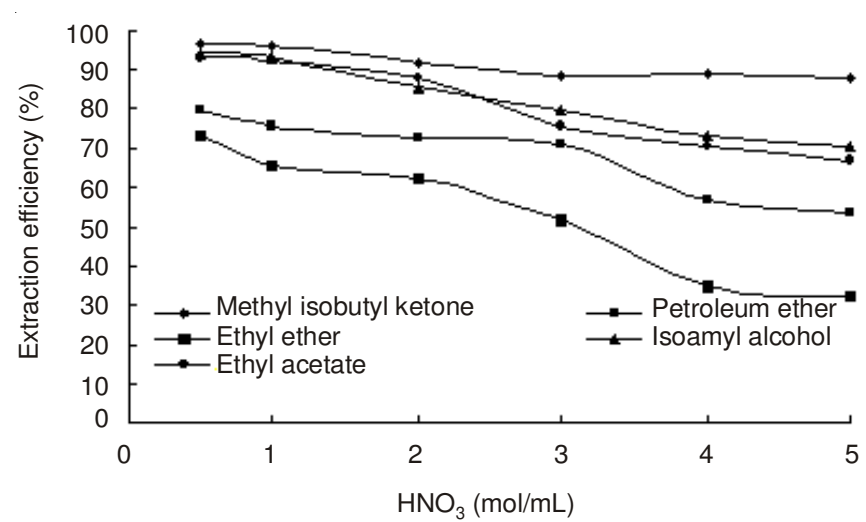

Fig.1. Effects of aqueous acidity and different extractants on the extraction efficiency of thiocyanate ions complex

the increase of solvent volume, which leveled off after the volume arrived at $7 \mathrm{~mL}$ (Fig. 2). Thus, the solvent volume was optimized $8 \mathrm{~mL}$ in the method.

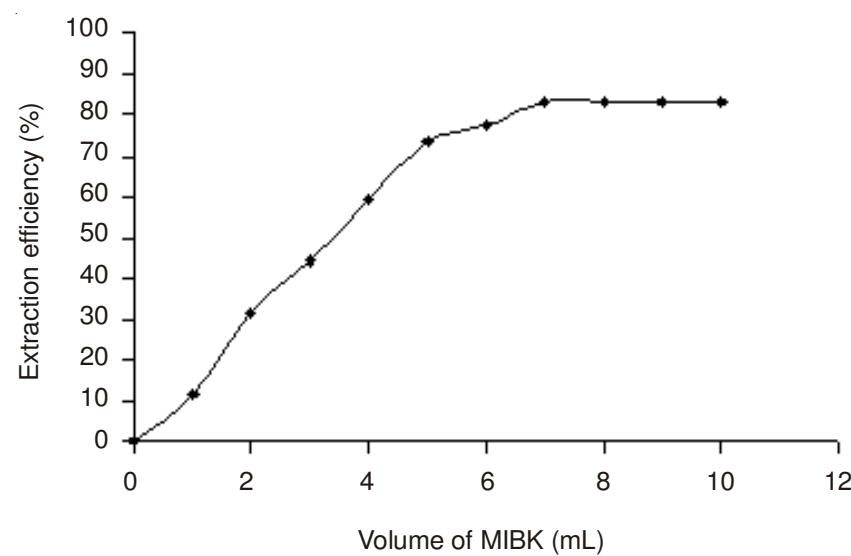

Fig. 2. Effect of methyl isobutyl ketone volume on the extraction efficiency of thiocyanate ions complex

Time of agitation and settlement: In accordance with the method, in 6 separatory funnels of $60 \mathrm{~mL}, 1 \mathrm{~mL}$ of $1 \mu \mathrm{g} / \mathrm{mL}$ mercury ion, $1.5 \mathrm{~mL}$ of $1 \mu \mathrm{g} / \mathrm{mL}$ thiocyanate, $1 \mathrm{~mL}$ of 1 $\mathrm{mol} / \mathrm{mL} \mathrm{HNO}_{3}$ and $6.5 \mathrm{~mL}$ water were added to make final volume of $10 \mathrm{~mL}$ in each. The agitation took place in the different time period after the addition of $8 \mathrm{~mL}$ methyl isobutyl ketone. It was found that the fluorescence intensity enhanced as the extraction time elongated. After $3 \mathrm{~min}$, the intensity stabilized. Followed the same manner, the settlement time was $0.5 \mathrm{~h}$ for the best separation between organic and aqueous phases.

Amount of mercury in the aqueous phase: In a series of 7 separatory funnels, based on the method, $1.5 \mathrm{~mL}$ of $1 \mu \mathrm{g} / \mathrm{mL}$ thiocyanate and $1 \mathrm{~mL}$ of $1 \mathrm{~mol} / \mathrm{mL}$ nitric acid were added in each, then $0.4,0.8,1,1.4,1.8,2,2.5 \mathrm{~mL}$ of $1 \mu \mathrm{g} / \mathrm{mL}$ mercury ion were added in the series, respectively, then in each funnel, water was added to make a final volume of $10 \mathrm{~mL}$. After the reaction inside the funnel completed, $8 \mathrm{~mL}$ of methyl isobutyl ketone were added and agitated. The organic phase was transferred when the separation of the two phases was throughly finished. Fig. 3 depicted that the fluorescence intensity arrived its stability when the solvent volume was $1 \mathrm{~mL}$, suggesting $1 \mathrm{~mL}$ used in the experiment. 


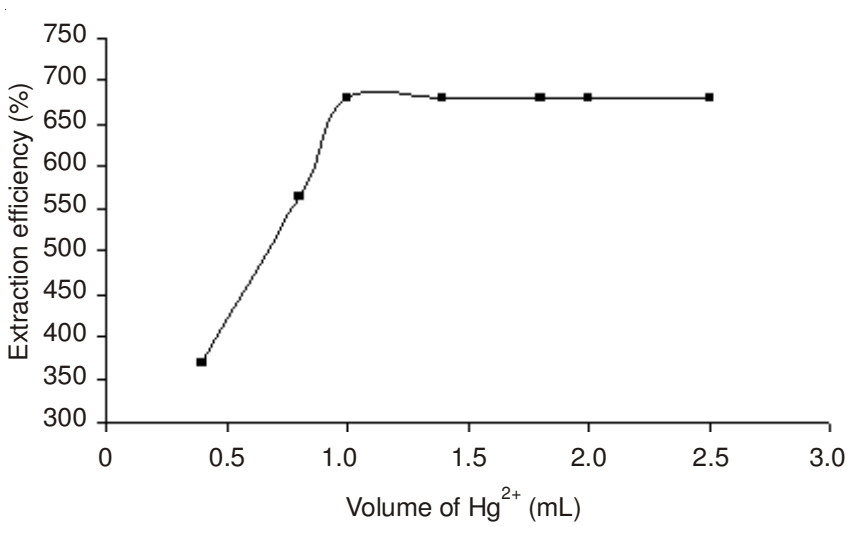

Fig. 3. Effect of $\mathrm{Hg}^{2+}$ amount on the extraction efficiency of thiocyanate ion complex

Interferences: Under experimental condition, the often occurring ions and the potential ions $\mathrm{Fe}^{3+}, \mathrm{Cu}^{2+}$ and $\mathrm{Mo}^{6+}$ which could complex with thiocyanate were examined for their interference. It was found that 1000 folds of $\mathrm{Ca}^{2+}, \mathrm{Mg}^{2+}, \mathrm{K}^{+}$, $\mathrm{Na}^{+}$and $\mathrm{NO}_{3}{ }^{-}, \mathrm{Cl}^{-}, \mathrm{Br}^{-}, \mathrm{I}^{-}, \mathrm{SO}_{4}{ }^{2-}$ did not generate any interference, 1000 folds of $\mathrm{Fe}^{3+}, \mathrm{Cu}^{2+}$ and $\mathrm{Mo}^{6+}$ did interfere the thiocyanate determination. However, in a real world, their amounts are much less than the added amounts, thus, their interference could be ignored.

Standard calibration curve and detection limit: In 6 of $60 \mathrm{~mL}$ separatory funnels, $1 \mathrm{~mL}$ of $1 \mu \mathrm{g} / \mathrm{mL}$ mercury ion solution, $1 \mathrm{~mL}$ of $1 \mathrm{~mol} / \mathrm{mL}$ nitric acid, $0.0,0.5,1,1.5,2$, $2.5 \mathrm{~mL}$ of $0.1 \mu \mathrm{g} / \mathrm{mL}$ thiocyanate solution were added, individually, then water was added to make each to final volume of $10 \mathrm{~mL}$. Each funnel was mixed thoroughly, $8 \mathrm{~mL}$ of methyl isobutyl ketone were added and agitated and rested for separation. The organic phase was transferred into $10 \mathrm{~mL}$ colorimetric tube and mercury was determined in terms of thiocyanate. In the optimum condition, the linear relationship between atomic fluorescence intensity and thiocyanate concentration of $0.2-150 \mathrm{ng} / \mathrm{mL}$ existed. The linear equation was $\mathrm{y}$ $=23 x+365.14$ with relative coefficient of 0.9927 . The detection limit of $1.33 \mathrm{ng} / \mathrm{mL}$ was obtained from the calculation on 3 times of standard deviation when a blank sample including all reagents without target was determined 11 times. The relative standard deviation was $2.1 \%$.

Sample analysis: The proposed method was applied to determine the thiocyanate in the samples from offshores in Xiamen City of Fujian Province and in Beihai City of Guangxi
Province in China. Meanwhile, the samples were spiked with standards, showing recoveries of 99.50-100.3\% listed in Table-1.

\begin{tabular}{ccccc}
\multicolumn{5}{c}{ TABLE-1 } \\
ANALYTICAL RESULTS OF SAMPLES AND \\
RECOVERIES $(\mathrm{N}=6)$
\end{tabular}

\section{Conclusion}

The optimum conditions were investigated for the extraction of complex between mercury and thiocyanate using methyl isobutyl ketone. It was found that the extraction efficiency was more than $95 \%$ when the aqueous acidity was $0.1 \mathrm{~mol} /$ $\mathrm{mL}$ and $8 \mathrm{~mL}$ of methyl isobutyl ketone was utilized. The linear relationship existed in the range of $0.1-150 \mathrm{ng} / \mathrm{mL}$ thiocyanate and the detection limit was $1.33 \mathrm{ng} / \mathrm{mL}$. When samples were determined, the recoveries were obtained in 99.5-100.3\%. This method showed simple operation, low cost performance and accuracy.

\section{REFERENCES}

1. U. Domanska and A. Marciniak, J. Chem. Thermodyn., 40, 860 (2008).

2. A. Khazaei, S. Rahmati, A. Khalafi-nezhad and S. Saednia, J. Fluor. Chem., 137, 123 (2012).

3. H.J. Palomares, F.O. Serrano and R. Lopez., Analysis, 17, 355 (1989).

4. T. Toida, T. Togawa, S. Tanabe and T. Imanari, J. Chromatogr. B: Biomed. Sci. Appl., 308, 133 (1984).

5. M. Królikowska, M. Karpinska and M. Królikowski, J. Chem. Thermodyn., 62, 1 (2013).

6. Y. Michigami, K. Fujii, K. Ueda and Y. Yamamoto, Analyst, 117, 1855 (1992).

7. U. Domanska and M. Laskowska, J. Chem. Thermodyn., 41, 645 (2009).

8. J. Cheng, P. Jandik and N. Avdalovic, Anal. Chim. Acta, 536, 267 (2005).

9. T. Esmadif, M. Kharoaf and S. Attiyata, J. Flow Injection Anal, 10, 33 (1993).

10. J.F. Van Staden and A. Botha, Anal. Chim. Acta, 403, 279 (2000).

11. M.A. Amin, Electrochim. Acta, 56, 2518 (2011).

12. E.Y. Cao, P. Gao, J.Y. Gui, F. Lu, D.A. Stern and A.T. Hubbard, J. Electroanal. Chem., 339, 311 (1992).

13. R. Jurczakowski and M. Orlik, J. Electroanal. Chem., 605, 41 (2007).

14. J.O. Hill and S. Korce, Thermochim. Acta, 154, 49 (1989).

15. V.R. Martín and O.J. de Blas, Anal. Chim. Acta, 274, 367 (1993).

16. R.K. Somasekhar and S.U. Muralikri, Chim. Acta Turc., 11, 351 (1983). 